\title{
Shifting spatial attention makes you flip: Exogenous visual attention triggers perceptual alternations during binocular rivalry
}

\author{
Chris L. E. Paffen and Stefan Van der Stigchel \\ Utrecht University, Utrecht, The Netherlands \\ and Helmholtz Institute, Utrecht, The Netherlands
}

\begin{abstract}
Although it has been argued that visual attention and the dynamics of binocular rivalry are closely linked, strong evidence for this proposition is still lacking. Here, we investigate how perceptual alternations during binocular rivalry are affected by spatial attention by employing a cuing paradigm. We show a tight link between the occurrence of perceptual alternations and the spatiotemporal properties of visual attention: Alternations occurred earlier and more frequently at locations where visual attention was summoned by an exogenous cue. We argue that cuing a location where rival images are presented leads to a transient increase in the effective contrast of these rival images. This transient increase in effective contrast increases the probability of an alternation at that location. Furthermore, we suggest that an occipito-fronto-parietal network known to be involved in selective attention and binocular rivalry mediates perceptual alternations by boosting the neural response at attended locations.
\end{abstract}

When the eyes are presented with dissimilar images at overlapping retinal locations, perception will alternate between the two images. This phenomenon is known as binocular rivalry and has fascinated scientists for nearly 200 years (Breese, 1899; Helmholtz, 1866/1925; Wheatstone, 1838; for recent reviews, see Alais \& Blake, 2005; Blake \& Logothetis, 2002; Tong, Meng, \& Blake, 2006). One of the important questions underlying binocular rivalry is the role of visual attention in the phenomenon. Many studies have implicated attention as being able to modulate the dynamics of the phenomenon (Chong \& Blake, 2006; Chong, Tadin, \& Blake, 2005; Lack, 1978; Meng \& Tong, 2004; Mitchell, Stoner, \& Reynolds, 2004; Ooi \& He, 1999; Paffen, Alais, \& Verstraten, 2006; van Ee, van Dam, \& Brouwer, 2005). It has even been argued that visual attention and binocular rivalry share underlying neural mechanisms (Leopold \& Logothetis, 1999).

The proposed link between visual attention and binocular rivalry is based on the premise that both involve selection of information. Visual attention is crucially involved in selecting relevant and filtering out irrelevant events from the enormous amount of information entering via the senses (Bundesen, 1990; Desimone \& Duncan, 1995). Likewise, during binocular rivalry, one image is selected as the dominant percept, at the cost of perceptual suppression of the other. Although previous studies have shown that the dynamics of binocular rivalry can be affected by attention (thereby suggesting a link between the phenomena), it remains unknown exactly how tightly the employment of attention is linked to the occurrence of perceptual alternations. Here, we argue that if there is a direct relation between visual attention and binocular rivalry, perceptual alternations should have the spatiotemporal characteristics of visual attention.

There are good reasons to expect a tight coupling between selecting a location by attention at a given time and the probability of having an alternation at that location. For one, attending a location boosts the neural activity to elements presented at that location (Brefczynski \& DeYoe, 1999; Datta \& DeYoe, 2009; Gandhi, Heeger, \& Boynton, 1999; Somers, Dale, Seiffert, \& Tootell, 1999). It has further been suggested that attending both rival images leads to a boost in the neural response, which increases the effective contrast of rivaling images (Paffen et al., 2006). Here, we put forward the idea that the boost in neural responses at cued locations transiently increases the effective contrast of both rivaling images. Since increases in effective contrast have been linked to an increase in the rate at which rival images alternate (Paffen et al., 2006), such a transient boost is likely to increase the probability of a perceptual alternation at a cued location.

To investigate this, we used an exogenous cuing paradigm to summon visual attention to a rivalry location (Posner, Snyder, \& Davidson, 1980). A task-irrelevant peripheral cue was presented at one of two rivalry locations. In Experiment 1, we investigated whether visual attention is captured reflexively by the cue by testing whether target detection would be facilitated at cued locations. In Experiment 2, participants were required to indicate perceptual alternations while a cue was presented at a rivalry loca- 
tion. If perceptual alternations are dependent on the locus of visual attention, perceptual alternations should follow the spatiotemporal dynamics of attention: Alternations should occur more frequently and earlier at the location of visual attention shortly after the cue is presented (i.e., the cued location) than at the uncued location.

\section{METHOD}

\section{Participants}

A total of 9 participants, all naive as to the purpose of the experiments, performed in the experiments. All had normal or correctedto-normal visual acuity.

\section{Apparatus and Stimuli}

The stimuli were presented using an Apple Dual $2 \mathrm{GHz}$ PowerPC G5 and a linearized LaCie Electron Blue IV 22-in. monitor $(100 \mathrm{~Hz}, 1,024 \times 768$ pixel resolution), using MATLAB and the Psychtoolbox extensions. Dichoptic presentation was achieved using a mirror stereoscope. The participants performed a cuing task (Experiment 1) and a rivalry task (Experiment 2) on similar displays. The basic display consisted of two images presented dichoptically (Figure 1). In each image, two Gabors were presented $3^{\circ}$ from the fixation cross. The Gabors had a spatial frequency of $1 \mathrm{cpd}$, a Gaussian envelope with a sigma of $0.5^{\circ}$, and a peak contrast of $99.5 \%$ Michelson. In one image, the two Gabors were tilted $45^{\circ}$ clockwise from vertical; in the other, the Gabors were tilted $-45^{\circ}$ from vertical. The Gabors had the same mean luminance as the background of the screen $\left(30.0 \mathrm{~cd} / \mathrm{m}^{2}\right)$. The cue (Experiments 1 and 2) consisted of two red bars $\left(1.7^{\circ}\right.$ wide, $0.2^{\circ}$ high, spaced $1.9^{\circ}$ from the middle); the target (Experiment 1$)$ consisted of a small green dot $\left(0.6^{\circ}\right.$ in diameter, presented at the center of the Gabor). The fixation cross was $0.4^{\circ}$ in diameter. Throughout the experiments, high-contrast fusion frames aided binocular fusion. Except for the absence of the green targets, the displays used in Experiment 2 were identical to those in Experiment 1.

\section{Procedure}

The participants first performed a cuing task (Experiment 1). On a single trial, the participants pressed the space bar to start a trial. After $500 \mathrm{msec}$, the Gabors were presented, which remained present for the rest of the trial. Between 1 and $1.5 \mathrm{sec}$ later (the precise onset was random within this interval), the cue appeared for $50 \mathrm{msec}$ at the left Gabor, the right Gabor, or the fixation cross. The target appeared for $150 \mathrm{msec}$ at the location of the left or right Gabor, $200 \mathrm{msec}$ after disappearance of the cue. All cues and targets were presented dichoptically and appeared at the same locations for each eye. The participants were instructed to report as quickly and accurately as possible the location of the target, by pressing one of two arrow keys. Feedback was given after incorrect responses. Combinations of cue and target locations resulted in 56 cue-valid trials (cue and target at the same Gabor location), 56 cue-invalid trials (cue and target at different Gabor locations), and 56 neutral trials (cue at fixation cross, target at Gabor) for each participant.

In the binocular rivalry experiment (Experiment 2), the task of the participants was to report perceptual alternations simultaneously for both Gabor locations; the participants pressed the left or right arrow
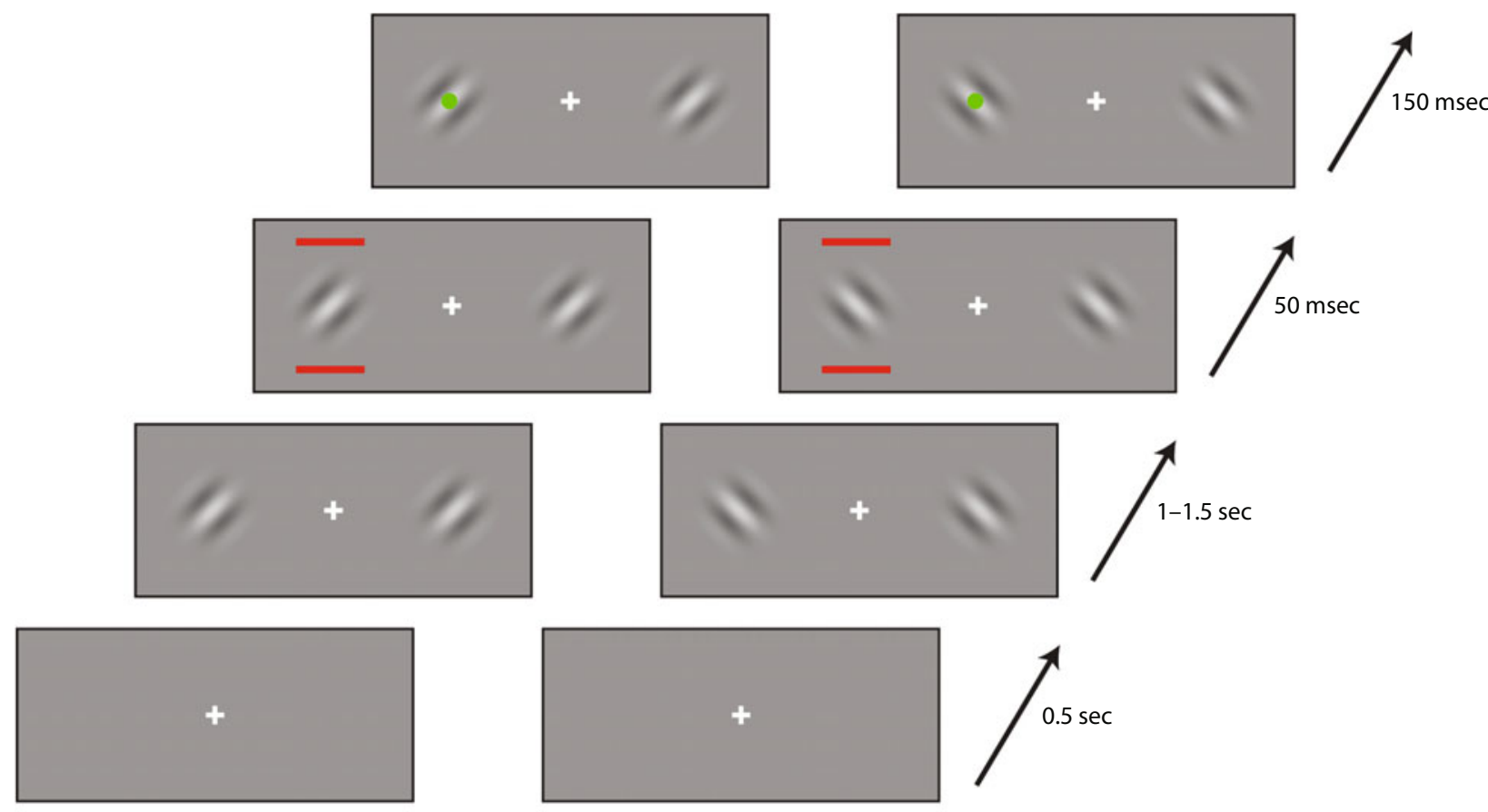

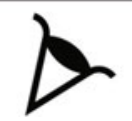

left eye
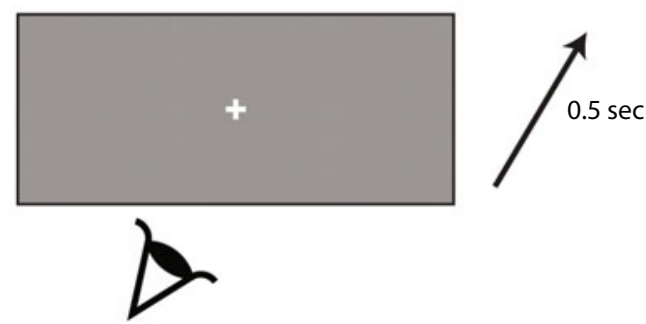

right eye

Figure 1. Schematic representation of a single cuing trial. A participant started a trial by pressing the space bar. The rival images appeared at the left and right sides of the fixation cross $500 \mathrm{msec}$ later. After 1-1.5 sec, the cue appeared for $50 \mathrm{msec}$, followed by the target, which was presented $200 \mathrm{msec}$ after disappearance of the cue. A trial was aborted after a response was made to the target location (Experiment 1) or after two alternations were reported for each rival image pair (Experiment 2). Except for the presentation of the target, the displays used in Experiments 1 and 2 were identical. 
key whenever an alternation was perceived. The stimulus remained present on the screen until two alternations were reported for each Gabor side. Reported alternations were counted after onset of the cue (the timing of the cue was similar to that in Experiment 1). Each participant performed 144 (48 cue-left, 48 cue-right, and 48 cue-atfixation-cross) trials.

\section{RESULTS}

\section{Experiment 1}

For Experiment 1, we calculated mean reaction times for correct trials (average accuracy was 96.5\%, SD = $2.2 \%$; no participant performed under $93.4 \%$ correct). The results replicated the classical cuing effect observed by Posner et al. (1980): Responses to targets at cued locations were faster than responses to targets at uncued locations (Figure 2A). In a repeated measures ANOVA with cue as a factor, there was a main effect of cue $[F(2,16)=34.2$, $p<.0001]$. Post hoc comparisons revealed benefits from the cue (responses were faster at the cued location than at the neutral location; $p<.05$ ), as well as costs (responses were slower at the uncued location than at the neutral location; $p<.001)$.

\section{Experiment 2}

The effect of cuing was markedly present in the occurrence of perceptual alternations (Figures $2 \mathrm{~B}$ and $2 \mathrm{C}$ ): The first alternation occurred most often at the location of the cue [one-sample $t$ test, fraction switch at cued location was larger than $.5 ; t(8)=3.6, p<.005]$, whereas the second alternation occurred most often at the uncued location [fraction switch at cued location was smaller than .5; $t(8)=2.4, p<.05]$.

Cuing also had a significant effect on the timing of alternations. A repeated measures ANOVA with factors of cue (cued, uncued, neutral) and switch number (first, second) revealed main effects for the cue and switch number
A

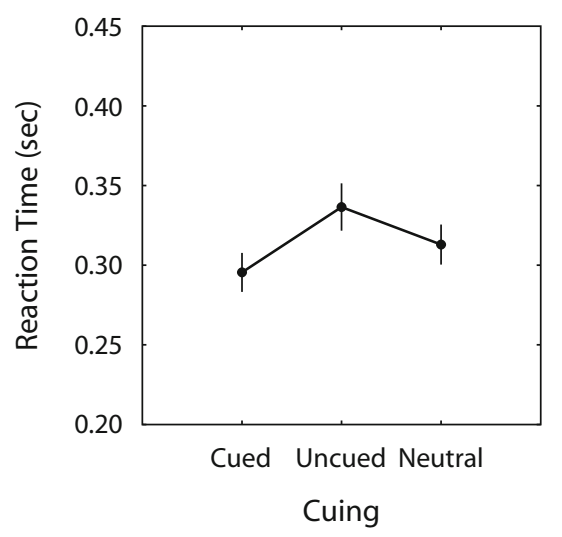

C

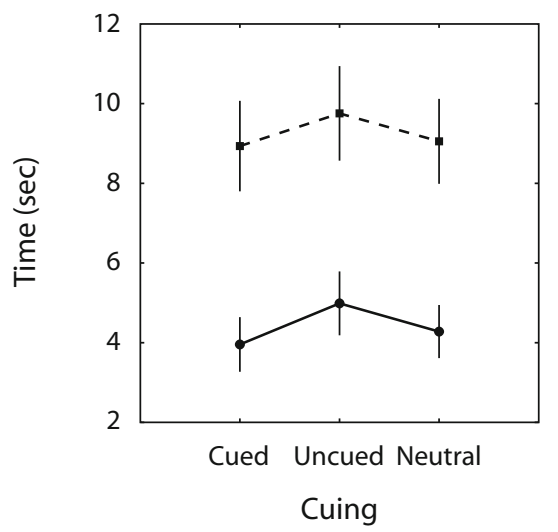

B

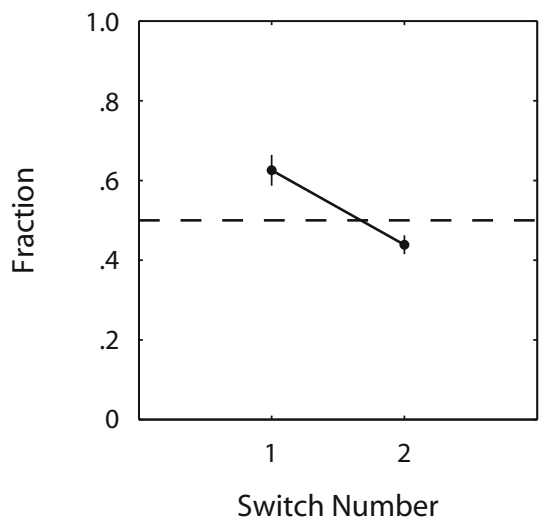

D

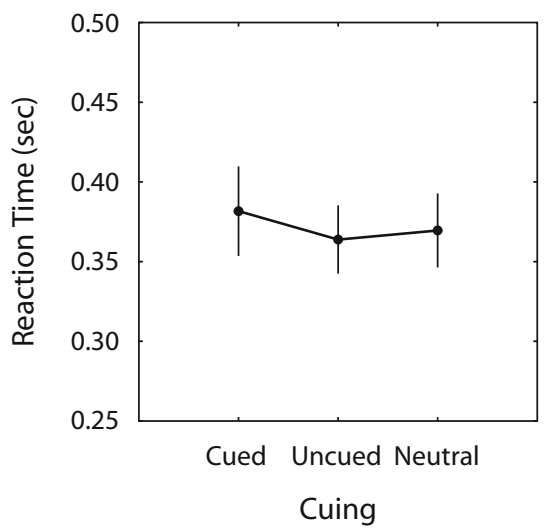

Figure 2. Results of Experiment 1 (A), Experiment 2 (B and C), and the first control experiment (D). Exogenous cuing led to faster responses at the cued side and to slower responses at the uncued side (panel A). As a result of cuing, the first perceptual alternation occurred more often at the cued side, whereas the second alternation occurred more often at the uncued side (panel B). In addition, the first (solid line with circles) and second (dashed line with squares) alternations occurred earlier at the cued location than at the uncued location (panel C). Reaction times to yoked stimuli were not different for cued, uncued, and neutral locations (panel D), refuting the possibility that the results of Experiment 2 were caused by differences in motor preparation. Error bars in all the panels represent standard errors of the means. 
factors [cue factor, $F(2,16)=6.3, p<.05$; switch number factor, $F(1,8)=104.7, p<.0001]$. Post hoc testing of the cue factor revealed that switches at the cued side occurred earlier than those at the uncued side ( $p<.05$, Bonferroni corrected). The main effect of the switch number factor is trivial: It indicates that the first switch occurs earlier than the second one. Importantly, however, we observed no interaction between switch number and cue $[F(2,7)=$ $0.6, p=.6]$. This indicates that the time between the first and second switches was not different between cued, uncued, and neutral locations. Thus, the cue affected the occurrence of perceptual alternations only before the first alternations.

\section{CONTROL EXPERIMENTS}

The results of Experiments 1 and 2 suggest that an exogenous shift of spatial attention triggers a perceptual alternation. However, before accepting the latter interpretation, we have to exclude alternative hypotheses.

A first alternative is that the different response times for perceptual alternations at cued and uncued locations were not caused by a change in the frequency of alternations but by differences in motor preparation. An observer might simply respond more quickly to an alternation at a cued location than to one at an uncued location, although the timing of the alternations was not different. We explicitly tested this hypothesis by measuring reaction times to yoked (simulated) perceptual alternations (as in Lee \& Blake, 2004, and Paffen et al., 2006). In an experiment in which 7 observers participated, we mimicked perceptual alternations by presenting a Gabor patch (with the same parameters as those in the previous experiments) whose orientation changed over time. The timing of the alternations was acquired by sampling from a Gamma distribution (commonly used to fit perceptual dominance durations of binocular rivalry; see, e.g., Levelt, 1967; Logothetis, Leopold, \& Sheinberg, 1996). A transition from one orientation to the other occurred by decreasing the contrast of Gabor 1, while simultaneously increasing the contrast of Gabor 2 along a Gaussian time window with a gamma of $0.1 \mathrm{sec}$. The stimulus in this experiment was presented binocularly to match the presentation in Experiments 1 and 2. The procedure used in this experiment was identical to that in the main binocular rivalry experiment (Experiment 2). Figure 2D shows reaction times to the first mimicked alternations after onset of the cue for cued, uncued, and neutral conditions. The differences in reaction time between the different conditions were not significant $[F(2,12)=1.6, p=.2]$. Differences in the timing of perceptual alternations were therefore not caused by the effects of attention on motor preparation.

The second alternative interpretation we consider concerns the possibility that the different timing of perceptual alternations was caused by the occurrence of eye movements. Because it has been shown that eye movements play a considerable role in binocular rivalry (van Dam \& van Ee, 2006a, 2006b), it is conceivable that the different timing of alternations at cued and uncued locations is the result of eye movements made to cued locations. To address this issue, 3 observers performed an experiment that was exactly the same as Experiment 2, but now while their eye movements were measured. Eye movements were measured using a video camera. In offline analysis, trials containing eye movements were excluded by a research assistant unaware of the goal of the analysis. This procedure led to the removal of 2,0 , and 9 trials out of a total of 144 trials per observer. This shows that very few eye movements are made in this type of paradigm. Figure 3 shows the results of an analysis that was the same as that performed on the data shown in Figures $2 \mathrm{~B}$ and $2 \mathrm{C}$, but now with trials containing eye movements excluded. In all observers, the first alternation occurred more often at the cued side than at the uncued side (Switch Number 1 in the top row of Figure 3), and the second alternation occurred more often at the uncued side, although this effect was weak in the second observer (Switch Number 2 in the top row). Similarly, the timing of the alternations shows the same profile as that in Experiment 2: Perceptual alternations occurred earlier at cued than at uncued locations (compare cued and uncued in the bottom row of Figure 3). We therefore exclude the possibility that eye movements caused the dynamics reported for Experiment 2.

\section{DISCUSSION}

The present study suggests that the locus of spatial attention modulates perceptual alternations during binocular rivalry. At locations where an attentional cuing benefit was observed, perceptual alternations were more likely to occur first. Also, perceptual alternations occurred earlier at cued locations than at uncued locations. Although the efficacy of the peripheral cue in causing shifts of attention was assessed offline, it was clear that the peripheral cue was effective in shifting attention on a majority of the trials. Importantly, in two control experiments, we showed that neither differences in motor preparation nor eye movements were driving the different timings of perceptual alternations caused by the peripheral cue. Together, these results demonstrate that perceptual alternations are triggered by the spatial location at which visual attention is exogenously allocated.

Our results complement those of studies showing that attention can modulate the dynamics of binocular rivalry by boosting the dominance of the attended image (Chong et al., 2005; Lack, 1978; Meng \& Tong, 2004; van Ee et al., 2005), can slow down the rate of perceptual alternation due to divided attention (Paffen et al., 2006), and can affect which image is initially perceived (Mitchell et al., 2004). Although these studies have shown that attention can modulate the dynamics of binocular rivalry, none of these studies was able to relate the occurrence of perceptual alternations to the spatiotemporal characteristics of visual attention.

The results of a study by Kanai, Moradi, Shimojo, and Verstraten (2005) are consistent with the present findings. In that study, flashing the background triggered alternations of stimuli, leading to bistable perception, such as rivalry-inducing images and the Necker cube. Although the transient nature of the visual stimulus that initiated 
C.P.

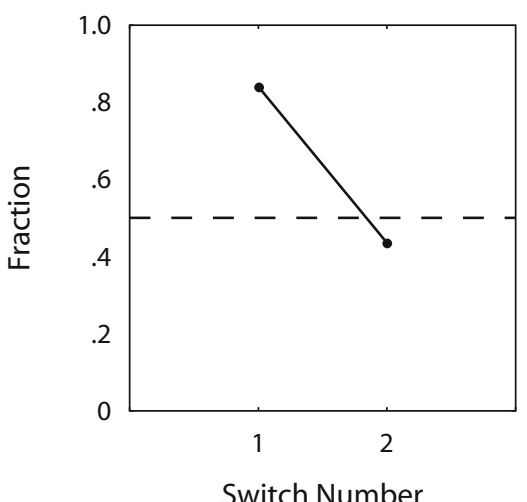

Switch Number

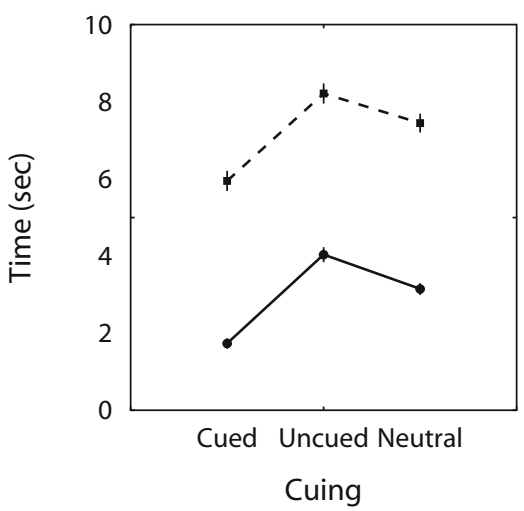

J.v.
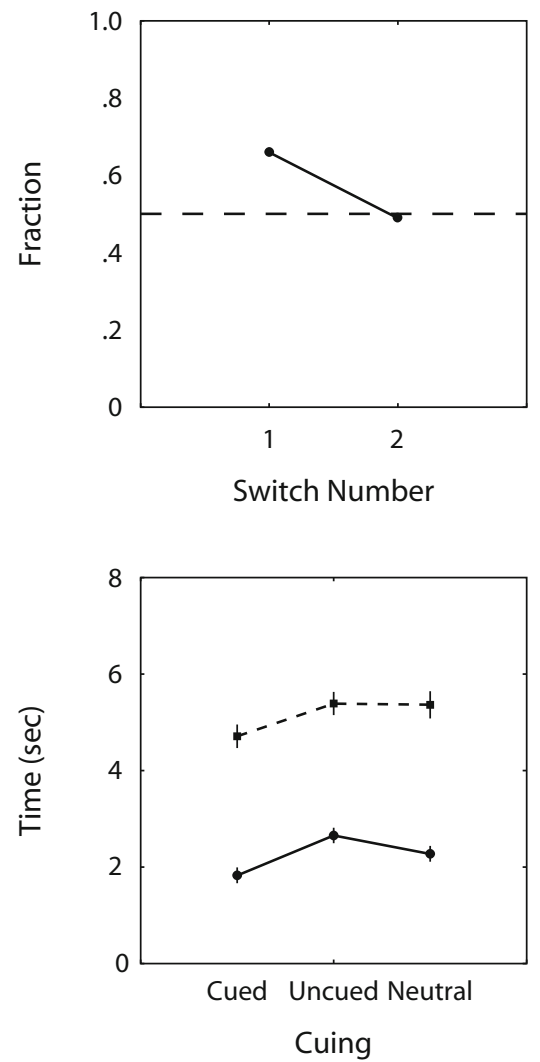

R.H.
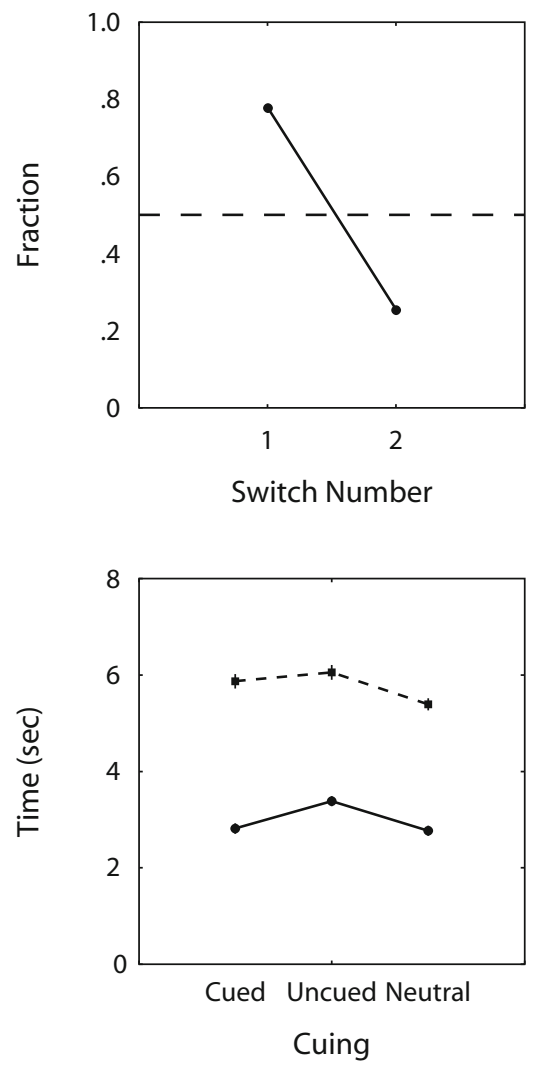

Figure 3. Results of the eye movement control for 3 observers. When trials containing eye movements were excluded, the first alternation was more often reported at the cued side, whereas the second alternation was more often reported at the uncued side (top row). In addition, the timing of alternations was still markedly affected by the cue: Alternations were reported earlier at the cued side than at the uncued side (bottom row). For the bottom row, the solid lines and circles represent the timing of the first perceptual alternations reported for the three locations; the dashed lines and squares represent the timing of the second perceptual alternations for these locations. The error bars represent standard errors of the means.

perceptual alternations was much higher in their study than in our study, it is conceivable that both results were caused by similar mechanisms. In fact, Kanai and colleagues already speculated that "our method of presenting a transient stimulus is closely related to exogenously triggered attention" (Kanai et al., 2005, p. 820). The present results therefore extend those of Kanai et al. by explicitly showing a tight relation between the time course of perceptual alternations and the spatiotemporal dynamics of visual attention. Furthermore, our study shows that shifting attention to a location in space evokes a perceptual alternation at that specific location.

There are many views on the underlying mechanisms of spatial attention. Attention is assumed to enhance the efficiency of processing (e.g., Posner, Nissen, \& Ogden, 1978), reduce stimulus uncertainty (e.g., Eckstein, Shimozaki, \& Abbey, 2002; Palmer, 1994), enhance the stimulus signal (e.g., Yeshurun \& Carrasco, 1999), reduce external noise (e.g., Lu \& Dosher, 1998), boost processing of the dominant surface (Brouwer \& van Ee, 2006), or boost processing of features or objects at the cued location (e.g., Liu, Slotnick, Serences, \& Yantis, 2003; Serences, Liu, \& Yantis, 2005). For the results presented here, we suggest that the higher prevalence of perceptual alternations at the attended location is caused by a transient, local boost of neural activity at the locus of the rival images. Such a boost in neural activity leads to an increase in the effective contrast of the images (Chong et al., 2005; Paffen et al., 2006). Metaphorically speaking, the temporary increase in effective contrast mimics an actual physical increase in luminance contrast. Such a transient increase in contrast is known to be able to trigger alternations during binocular rivalry (Blake, Westendorf, \& Fox, 1990; Walker \& Powell, 1979). Therefore, attending a specific location similarly affects the dynamics of binocular rivalry as an abrupt contrast change in the rival images.

In a recent study by Kang, Heeger, and Blake (2009), the interpretation that the dynamics of perceptual alternations can be modulated by shifts of attention was refuted. In their paradigm, perceptual alternations in a central region were triggered by brief contrast increments within peripheral regions. In contrast to our study, however, the contrast increments were part of the rival images, whereas in our paradigm, the peripheral cues were distinct from the rival images. Because of the differences between the paradigms, it might be that the perceptual alternations in 
their study were, indeed, not evoked by attentional shifts. Our Experiment 1 convincingly shows that the peripheral cues did produce attentional shifts in our study, providing evidence for the crucial role of spatial attention in producing perceptual alternations.

Our findings are in line with the results of Ooi and He (1999), who showed that presenting a cue to the suppressed image increased the probability that this stimulus regains perceptual dominance. Likewise, Hancock and Andrews (2007) recently showed that both voluntary and involuntary attention increases the predominance of the image to which a cue is presented. These findings can be explained by arguing that exogenous attention is capable of bringing a suppressed stimulus back to dominance and increasing the dominance of the attended image, because of a boost of neural activity associated with that image. Note that we presented the cue to both eyes, allocating visual attention to both the suppressed and the dominant stimuli. Our findings therefore extend the results of Ooi and $\mathrm{He}$ and of Hancock and Andrews by showing that allocating attention to both images triggers a perceptual alternation. In addition, our results show that the occurrence of perceptual alternations is closely coupled to the spatiotemporal dynamics of attention.

The present findings provide support for the proposition that binocular rivalry and visual attention are closely linked (Leopold \& Logothetis, 1999): Selecting a location by spatial attention increased the probability of an alternation at that location. Moreover, it has been claimed that neural networks involved in selective attention overlap with those involved in perceptual alternations during binocular rivalry: A fronto-parietal network involved in selective attention (Desimone \& Duncan, 1995; Nobre et al., 1997; Posner \& Dehaene, 1994) has also been implicated in the mediating of perceptual alternations during binocular rivalry (Cosmelli et al., 2004; Lumer, Friston, \& Rees, 1998; Lumer \& Rees, 1999) and in attentional control over a bistable Necker cube (Slotnick \& Yantis, 2005). Moreover, coactivation of frontal and occipital areas has been linked to perceptual switches during binocular rivalry (Cosmelli et al., 2004). Such coordinated activity between occipital and frontal areas has been argued to be essential for forming a conscious percept (Crick \& Koch, 2003). Although there is ongoing debate on the neuroanatomical underpinnings of visual attention and bistable perception (for one, the role of frontal areas in bistable perception is debated; see Kamphuisen, Bauer, \& van Ee, 2008; Raemaekers, van der Schaaf, van Ee, \& van Wezel, 2009), our results support the claim that neural networks involved in visual attention at least partly overlap with those involved in bistable perception.

\section{AUTHOR NOTE}

C.L.E.P. is supported by a VENI grant from the Netherlands Organization for Scientific Research (NWO). Correspondence concerning this article should be addressed to C. L. E. Paffen, Division of Experimental Psychology, Faculty of Social Sciences, Utrecht University, Utrecht, The Netherlands (e-mail: c.l.e.paffen@uu.nl).

\section{REFERENCES}

Alais, D., \& Blake, R. (Eds.) (2005). Binocular rivalry. Cambridge, MA: MIT Press.

Blake, R., \& Logothetis, N. K. (2002). Visual competition. Nature Reviews Neuroscience, 3, 13-21.

Blake, R., Westendorf, D., \& Fox, R. (1990). Temporal perturbations of binocular rivalry. Perception \& Psychophysics, 48, 593-602.

Breese, B. B. (1899). On inhibition. Psychological Monographs, 3, $1-65$.

BREFCZYNSKI, J. A., \& DeYoe, E. A. (1999). A physiological correlate of the "spotlight" of visual attention. Nature Neuroscience, 2, 370-374.

Brouwer, G. J., \& VAN Ee, R. (2006). Endogenous influences on perceptual bistability depend on exogenous stimulus characteristics. $V i$ sion Research, 46, 3393-3402.

Bundesen, C. (1990). A theory of visual attention. Psychological Review, 97, 523-547.

Chong, S. C., \& Blake, R. (2006). Exogenous attention and endogenous attention influence initial dominance in binocular rivalry. Vision Research, 46, 1794-1803.

Chong, S. C., Tadin, D., \& Blake, R. (2005). Endogenous attention prolongs dominance durations in binocular rivalry. Journal of Vision, 5(11), 1004-1012.

Cosmelli, D., David, O., Lachaux, J.-P., Martinerie, J., Garnero, L., Renault, B., \& Varela, F. (2004). Waves of consciousness: Ongoing cortical patterns during binocular rivalry. NeuroImage, 23, 128-140.

Crick, F., \& КосH, C. (2003). A framework for consciousness. Nature Neuroscience, 6, 119-126.

Datta, R., \& DeYoe, E. A. (2009). I know where you are secretly attending! The topography of human visual attention revealed with fMRI. Vision Research, 49, 1037-1044.

Desimone, R., \& Duncan, J. (1995). Neural mechanisms of selective visual attention. Annual Review of Neuroscience, 18, 193-222.

Eckstein, M. P., Shimozaki, S. S., \& Abbey, C. K. (2002). The footprints of visual attention in the Posner cueing paradigm revealed by classification images. Journal of Vision, 2(1), 25-45.

Gandhi, S. P., Heeger, D. J., \& Boynton, G. M. (1999). Spatial attention affects brain activity in human primary visual cortex. Proceedings of the National Academy of Sciences, 96, 3314-3319.

HANCOCK, S., \& ANDREWS, T. J. (2007). The role of voluntary and involuntary attention in selecting perceptual dominance during binocular rivalry. Perception, 36, 288-298.

Helmholtz, H. von (1925). Treatise on physiological optics (Vol. 3; J. P. C. Southall, Ed.). New York: Dover. (Original work published 1866)

Kamphuisen, A., Bauer, M., \& van Ee, R. (2008). No evidence for widespread synchronized networks in binocular rivalry: MEG frequency tagging entrains primarily visual cortex. Journal of Vision, 8(5), 1-8.

Kanai, R., Moradi, F., Shimojo, S., \& Verstraten, F. A. J. (2005). Perceptual alternation induced by visual transients. Perception, 34, 803-822.

Kang, M. S., HeEger, D., \& Blake, R. (2009). Periodic perturbations producing phase-locked fluctuations in visual perception. Journal of Vision, 9(8), 1-12.

LACK, L. C. (1978). Selective attention and the control of binocular rivalry. The Hague: Mouton.

LEe, S. H., \& BLAKE, R. (2004). A fresh look at interocular grouping during binocular rivalry. Vision Research, 44, 983-991.

LEOPOLD, D. A., \& Logothetis, N. K. (1999). Multistable phenomena: Changing views in perception. Trends in Cognitive Sciences, 3, 254264.

LeVelt, W. J. M. (1967). Note on the distribution of dominance times in binocular rivalry. British Journal of Psychology, 58, 143-145.

Liu, T., Slotnick, S. D., Serences, J. T., \& Yantis, S. (2003). Cortical mechanisms of feature-based attentional control. Cerebral Cortex, 13, 1334-1343.

Logothetis, N. K., Leopold, D. A., \& Sheinberg, D. L. (1996). What is rivaling during binocular rivalry? Nature, 380, 621-624.

Lu, Z.-L., \& Dosher, B. A. (1998). External noise distinguishes attention mechanisms. Vision Research, 38, 1183-1198. 
Lumer, E. D., Friston, K. J., \& Rees, G. (1998). Neural correlates of perceptual rivalry in the human brain. Science, 280, 1930-1934.

Lumer, E. D., \& Rees, G. (1999). Covariation of activity in visual and prefrontal cortex associated with subjective visual perception. Proceedings of the National Academy of Sciences, 96, 1669-1673.

Meng, M., \& Tong, F. (2004). Can attention selectively bias bistable perception? Differences between binocular rivalry and ambiguous figures. Journal of Vision, 4(7), 539-551.

Mitchell, J. F., Stoner, G. R., \& Reynolds, J. H. (2004). Objectbased attention determines dominance in binocular rivalry. Nature, 429, 410-413.

Nobre, A. C., Sebestyen, G. N., Gitelman, D. R., Mesulam, M. M., FRACKOWIAK, R. S., \& FRITH, C. D. (1997). Functional localization of the system for visuospatial attention using positron emission tomography. Brain, 120, 515-533.

OoI, T. L., \& He, S. (1999). Binocular rivalry and visual awareness: The role of attention. Perception, 28, 551-574.

Paffen, C. L. E., Alais, D., \& Verstraten, F. A. J. (2006). Attention speeds binocular rivalry. Psychological Science, 17, 752-756.

PALmer, J. (1994). Set-size effects in visual search: The effect of attention is independent of the stimulus for simple tasks. Vision Research, 34, 1703-1721.

Posner, M. I., \& Dehaene, S. (1994). Attentional networks. Trends in Neurosciences, 17, 75-79.

Posner, M. I., Nissen, M. J., \& Ogden, W. C. (1978). Attended and unattended processing modes: The role of set for spatial location. In H. L. Pick, Jr., \& E. Saltzman (Eds.), Modes of perceiving and processing information (pp. 137-157). Hillsdale, NJ: Erlbaum.

Posner, M. I., Snyder, C. R. R., \& Davidson, B. J. (1980). Attention and the detection of signals. Journal of Experimental Psychology: General, 109, 160-174.

Raemaekers, M., van der SchaAf, M. E., van Ee, R., \& VAn Wezel, R. J. A. (2009). Widespread fMRI activity differences between perceptual states in visual rivalry are correlated with differences in observer biases. Brain Research, 1252, 161-171.
Serences, J. T., LiU, T., \& Yantis, S. (2005). Parietal mechanisms of attentional control: Locations, features and objects. In L. Itti, G. Rees, \& J. Tsotsos (Eds.), Neurobiology of attention (pp. 35-41). New York: Academic Press.

Slotnick, S. D., \& Yantis, S. (2005). Common neural substrates for the control and effects of visual attention and perceptual bistability. Cognitive Brain Research, 24, 97-108.

Somers, D. C., Dale, A. M., Seiffert, A. E., \& Tootell, R. B. (1999). Functional MRI reveals spatially specific attentional modulation in human primary visual cortex. Proceedings of the National Academy of Sciences, 96, 1663-1668.

Tong, F., Meng, M., \& Blake, R. (2006). Neural bases of binocular rivalry. Trends in Cognitive Sciences, 10, 502-511.

van Dam, L. C. J., \& van EE, R. (2006a). Retinal image shifts, but not eye movements per se, cause alternations in awareness during binocular rivalry. Journal of Vision, 6(11), 1172-1179.

VAN DAM, L. C. J., \& VAN Ee, R. (2006b). The role of saccades in exerting voluntary control in perceptual and binocular rivalry. Vision Research, 46, 787-799.

van Ee, R., van Dam, L. C. J., \& Brouwer, G. J. (2005). Voluntary control and the dynamics of perceptual bi-stability. Vision Research, 45, 41-55.

Walker, P., \& Powell, D. J. (1979). The sensitivity of binocular rivalry to changes in the nondominant stimulus. Vision Research, 19, 247-249.

Wheatstone, C. (1838). Contributions of the physiology of vision: Part the first. On some remarkable, and hitherto unobserved, phenomena of binocular vision. Philosophical Transactions of the Royal Society, 128, 371-394.

Yeshurun, Y., \& Carrasco, M. (1999). Spatial attention improves performance in spatial resolution tasks. Vision Research, 39, 293-306.

(Manuscript received August 11, 2009; revision accepted for publication February 10, 2010.) 